\title{
Diretrizes para Características Didáticas de Manuais e Vídeo Tutoriais de Jogos Analógicos
}

\section{Guidelines for Didactic Characteristics of Tabletop Games' Manuals and Video Tutorials}

\author{
LÉSTE , João \\ LEUI - PPGDesign - PUC-Rio, Mestrando \\ jvleste95@gmail.com \\ Mont'Alvão, Claudia \\ LEUI - PPGDesign - PUC-Rio, Professora Doutora \\ cmontalvao@puc-rio.br
}

\begin{abstract}
RESUMO
O presente artigo visa analisar as características necessárias de manuais de jogos analógicos, de acordo com as determinações do Código de Defesa do Consumidor, além de comparar, sob a ótica da ergonomia informacional, as características dos manuais impressos - presentes em todos os jogos analógicos - e dos vídeo tutoriais relativos aos mesmos jogos. Para tanto, três jogos serão investigados: Coup, sobre o qual existem diversos vídeo tutoriais não oficiais; Santorini, que possui um canal oficial no YouTube, majoritariamente dedicado a explicar o jogo através de vários vídeos curtos; e Nemesis, cuja empresa produtora realizou uma parceria com um canal preexistente no YouTube para produzir um vídeo tutorial extenso e oficial. Todas as comparações foram feitas usando tabelas que detalham as características de cada meio de explicação e comentários subsequentes.
\end{abstract}

Manuais de Jogos, Vídeo Tutoriais, Jogos Analógicos, Ergonomia Informacional, PROCON.

\begin{abstract}
This article intends to analyze which characteristics tabletop games' manuals ought to have in order to comply with Brazilian's Consumer Protection Codes, while comparing, from an informational ergonomics perspective, these same manuals - that need to be present in every sold game - with video tutorials about the same games. To do such, three games will be analyzed: Coup, about which there are many of unofficial game tutorials; Santorini, whose production company has an official YouTube channel, mostly dedicated to explaining the game with many short videos; and Nemesis, whose company partnered with an previously existing YouTube channel in order to produce an extensive official video-tutorial. All comparisons will be made via spreadsheets detailing the characteristics of each medium of explanation and further commentary about them.
\end{abstract}

Game manuals, Video-Tutorials, Tabletop Games, Informational Ergonomics, PROCON. 


\section{$17^{\circ}$ ERGODESIGN \& USIHC 2019}

PUC-Rio, 11 a 13 de dezembro

Rio de Janeiro, RJ, Brasil $17^{\circ}$ Ergodesign - Congresso Internacional de Ergonomia e Usabilidade de Interfaces Humano Tecnológica: Produto, Informações Ambientes Construídos e Transporte

$17^{\circ}$ USIHC - Congresso Internacional de Ergonomia e Usabilidade de Interfaces Humano Computador

\section{INTRODUÇÃO}

O meio dos jogos analógicos apresenta uma problemática pouco explorada até o momento no meio acadêmico, especialmente o brasileiro: a baixa qualidade de muitos dos manuais de instruções fornecidos pelas produtoras de jogos, do ponto de vista ergonômico. É de conhecimento geral que a tarefa de ler manuais não é agradável para usuários desse tipo de produto - situação que é frequentemente endereçada, seja por jogadores amadores ou por profissionais (MACKLIN, 2015) e pesquisadores da área (HAM, 2016).

Apesar dos esforços de alguns profissionais da área, a exemplo dos colaboradores do site Board Game Design Lab ${ }^{1}$, que reúne uma série de artigos que fornecem algumas diretrizes e dicas para a produção de manuais mais adequados ao público, muitos dos exemplares produzidos nos últimos anos ainda apresentam uma série de inadequações, que tornam a tarefa de leitura dos manuais ainda mais onerosa, corroborando com as baixas expectativas dos usuários. Isso se deve, entre outros fatores, ao fato de que não há nenhuma regulamentação por parte da legislação brasileira sobre boas práticas da escrita de manuais, permitindo que cada empresa siga diretrizes próprias, gerando grandes discrepâncias entre os resultados finais de manuais de diferentes jogos.

Paralelamente, está se consolidando um novo nicho de formas de ensinar e aprender as regras de jogos analógicos: os vídeo tutoriais explicativos, tanto oficiais produzidos pela editora do jogo - quanto não oficiais - produzidos, geralmente, por influenciadores digitais do meio dos jogos analógicos.

Nesse contexto, o presente artigo visa fazer uma análise comparativa exploratória entre estes dois tipos distintos de documentos, a fim de identificar características positivas presentes nos vídeo tutoriais que possam justificar o crescimento deste nicho e, posteriormente, serem adaptadas à linguagem textual dos manuais. Para realizar a análise, foram selecionados três jogos e, em função da interação com os vídeos e manuais disponíveis, foram elaboradas tabelas comparativas, comentadas posteriormente.

Primeiramente, ocorreu uma investigação inicial sobre a disponibilidade de vídeo tutoriais em bancos de dado da internet, diferenciando-os entre oficiais e não oficiais. Em função dela, foram selecionados os seguintes jogos:

- Coup ${ }^{2}$, lançado em 2012 e nomeado para diversos prêmios. O jogo se mantém popular até hoje, possibilitando que fosse importado para o Brasil e recebesse uma nova expansão, além de uma reformulação no projeto artístico das cartas aclamado pelo público - e gráfico do manual. Por consequência, diversos canais dedicados ao teste, avaliação e crítica de jogos produziram vídeo tutoriais não oficiais para ele, apresentando um espaço amostral significativo;

- Nemesis, cuja editora fez uma parceria com um canal preexistente no YouTube para produzir um extenso vídeo tutorial oficial para o jogo, que inclui um elemento essencial para a boa organização das informações de qualquer documento: indexação - tornando-o um excelente objeto de estudo;

- Santorini, cuja editora possui um canal do YouTube com vídeo tutoriais oficiais, primariamente dedicados à explicação de diferentes aspectos do jogo. A produção de vídeos curtos e complementares apresenta um contraponto interessante aos

\footnotetext{
${ }^{1}$ Repositório disponível em https://www.boardgamedesignlab.com/rules/\#writing

${ }^{2}$ Versão reduzida de Coup d'État, do francês, que traduzido para o português significa "Golpe de Estado" - conceito no qual a premissa do jogo se baseia.
} 


\section{$17^{\circ}$ ERGODESIGN \& USIHC 2019}

PUC-Rio, 11 a 13 de dezembro

Rio de Janeiro, RJ, Brasil $17^{\circ}$ Ergodesign - Congresso Internacional de Ergonomia e Usabilidade de Interfaces Humano Tecnológica: Produto, Informações Ambientes Construídos e Transporte

$17^{\circ}$ USIHC - Congresso Internacional de Ergonomia e Usabilidade de Interfaces Humano Computador

exemplos anteriores, dialogando com a proposta da campanha de financiamento do jogo: produção de expansões à medida que a empresa adquira mais capital;

O critério de escolha para esses diferentes tipos de vídeos produzidos foi que a pluralidade desses tipos de representações oferece um espaço amostral diversificado e, portanto, pertinente para uma análise comparativa e exploratória do contexto do mercado. Além disso, a investigação inicial de diferentes facetas desse nicho é o primeiro passo na investigação de qual das modalidades de vídeo é mais eficiente em complementar situações e contextos de usuários que os manuais impressos são incapazes (ou possuem extrema dificuldade) de contemplar, a exemplo de pessoas analfabetas ou pessoas cegas, conferindo mais acessibilidade ao meio dos jogos analógicos.

\title{
2. EM DEFESA DA REGULAMENTAÇÃO DOS MANUAIS
}

De acordo com a legislação brasileira, todo e qualquer produto comercializado em território nacional precisa ser acompanhado de instruções didáticas e ilustradas, adequadas ao contexto específico de uso em questão, conforme o Código de Defesa do Consumidor:

\begin{abstract}
Art. 50. A garantia contratual é complementar à legal e será conferida mediante termo escrito. Parágrafo único. O termo de garantia ou equivalente deve ser padronizado e esclarecer, de maneira adequada, em que consiste a mesma garantia, bem como a forma, o prazo e o lugar em que pode ser exercitada e os ônus a cargo do consumidor, devendo ser-lhe entregue, devidamente preenchido pelo fornecedor, no ato do fornecimento, acompanhado de manual de instrução, de instalação e uso do produto em linguagem didática, com ilustrações. (SENADO FEDERAL, 2017)
\end{abstract}

Todavia, apesar de não haver dúvidas da necessidade que qualquer jogo analógico seja acompanhado do manual de uso adequado - o manual de regras do jogo -, fica à cargo dos designers, produtores e editores interpretarem o significado de "linguagem didática, com ilustrações" ao projetarem manual. A falta de uma definição mais precisa e regulamentada do que caracteriza a linguagem didática e de como devem ser aplicadas as imagens faz com que os manuais apresentem características altamente discrepantes, dificultando a percepção e a definição de diretrizes adequadas para os mesmos.

Analisando outros tipos de produtos, pode-se constatar que existe uma categoria no mercado que possui regras e regulamentações sobre suas instruções de uso bastante rigorosas: produtos alimentícios. Em breve observação, percebe-se que todo produto alimentício industrializado possui, em sua embalagem, as seguintes informações (no mínimo): data de fabricação e validade; ingredientes; tabela nutricional; peso líquido; avisos sobre agentes alergênicos; instruções de armazenamento; e instruções de consumo.

Naturalmente, no caso de alimentos, é imprescindível que todas as informações pertinentes estejam presentes na embalagem, visto que o consumo inadequado de alguns destes produtos pode acarretar problemas graves de saúde. Portanto, a regulamentação do tipo de informações que devem estar presentes nas embalagens ocorre "considerando que a rotulagem nutricional facilita ao consumidor conhecer as propriedades nutricionais dos alimentos, contribuindo para um consumo adequado dos mesmos;" (ANVISA, 2003).

Portanto, para que esses dois objetivos fossem atingidos, foram estabelecidas uma série de normas que definem a forma como essas informações devem ser explicitadas - a fim de que elas possam ser apreendidas e interpretadas adequadamente pelos consumidores. Nesse sentido, mesmo tendo em mente que, em vias gerais, o contato com 


\section{$17^{\circ}$ ERGODESIGN \& USIHC 2019}

PUC-Rio, 11 a 13 de dezembro Rio de Janeiro, RJ, Brasil $17^{\circ}$ Ergodesign - Congresso Internacional de Ergonomia e Usabilidade de Interfaces Humano Tecnológica: Produto, Informações Ambientes Construídos e Transporte

$17^{\circ}$ USIHC - Congresso Internacional de Ergonomia e Usabilidade de Interfaces Humano Computador

jogos analógicos confere de pouco a nenhum risco para os usuários, entende-se que a conclusão de que "a fim de garantir a qualidade das informações passadas para o consumidor deve-se estabelecer diretrizes sobre como essas informações serão expressadas" se aplica, também, ao contexto dos manuais de jogos analógicos.

Ademais, essa conclusão é corroborada pela Constituição Federal de 1988, visto que ela também garante "a educação e divulgação sobre o consumo adequado dos produtos e serviços (...)" e considera que "A oferta e apresentação de produtos ou serviços devem assegurar informações corretas, claras, precisas, ostensivas e em língua portuguesa sobre suas características, qualidades, quantidade, composição (...)". Desta forma, faz-se valer a conclusão de que a regulamentação de que informações devem estar presentes nos manuais de jogos - e da forma como devem ser diagramadas, projetadas e ilustradas garante os direitos de acesso à informação dos consumidores, estando de acordo com os interesses da Constituição.

\section{A DIDÁTICA E A ERGONOMIA DOS MANUAIS}

A leitura do manual jogos é um processo informativo e de aprendizado, visto que os usuários devem adquirir novas informações e inferir como aplicá-las no contexto de jogo. Dessa forma, entende-se que é necessário motivá-los a se engajar nesse processo, além de torná-lo o menos oneroso possível. Portanto, a fim de identificar as possíveis diretrizes que possam contribuir com o caráter didático dos mesmos, foi feita uma breve pesquisa documental e bibliográfica de artigos, livros e documentos oficiais que discutem didática e processos educativos.

Durante os últimos dois anos, o Ministério da Educação coordenou a produção do Guia Digital do Programa Nacional do Livro Didático de 2020 (PNLD), que envolveu aproximadamente 100 profissionais, mais 20 revisores, da área de educação - e áreas correlatas. Nesse documento, são detalhados critérios importantes e pertinentes à seleção de materiais didáticos para serem usados no ambiente escolar. Dentre eles, vale ressaltar o trecho que explica a necessidade da contextualização do conhecimento que será aprendido:

Quais as finalidades da escola no presente? Qual o perfil de estudante que essa escola recebe? Qual formação se pretende dar a ele no espaço escolar? Preparar para o futuro ou para o presente? As perguntas admitem respostas variadas, mas todas elas acompanham a necessidade urgente de se mobilizar atividades e recursos metodológicos capazes de estimular o interesse do(a) estudante, de aguçar a criatividade e promover aprendizagens significativas. Sem aprendizagens significativas, plurais, contextualizadas, não há resposta possível a essas e outras questões concernentes à escola. (MINISTÉRIO DA EDUCAÇÃO, 2019)

Apesar de o texto ter sido produzido para o contexto escolar, entende-se que o ponto central dos questionamentos é estabelecer que a qualidade de qualquer aprendizado depende de que o conteúdo a ser apreendido seja significativo e alinhado ao contexto de quem aprende. Nesse sentido, é evidente que uma das principais formas de tornar o aprendizado relevante é informar de antemão qual sua aplicação prática - para que ele serve - e qual seu impacto na vida de quem o aprende:

Ao iniciar uma aula, pode-se dizer: "Agora vamos aprender a respeito da valência", o que do ponto de vista da motivação não tem valor. Seria muito mais proveitoso que se informasse inicialmente o estudante que os 


\section{$17^{\circ}$ ERGODESIGN \& USIHC 2019 \\ PUC-Rio, 11 a 13 de dezembro \\ Rio de Janeiro, RJ, Brasil}

$17^{\circ}$ Ergodesign - Congresso Internacional de Ergonomia e Usabilidade de Interfaces Humano Tecnológica: Produto, Informações Ambientes Construídos e Transporte

$17^{\circ}$ USIHC - Congresso Internacional de Ergonomia e Usabilidade de Interfaces Humano Computador

princípios da valência o tornariam apto a compreender a composição molecular dos resultantes de reações químicas e a dominar alguns outros procedimentos realmente úteis. É evidente que, para o estudante, a chave para o motivo da realização é a concepção da ação. Ele deve querer tornar-se capaz de fazer alguma coisa. (GAGNÉ, 1973, p. 192)

Portanto, para que haja motivação, deve haver, também um objetivo. Dessa forma, o aprendizado é o processo através do qual alguém se torna competente na realização de uma determinada tarefa, considerando "competência" como a capacidade de resolução de problemas ao acessar os conhecimentos previamente adquiridos - quando pertinentes à situação (MINISTÉRIO DA EDUCAÇÃO, 2019).

Desta forma, para que este conhecimento se traduza ao contexto do aprendizado das regras de jogos analógicos, é necessário estabelecer quais os objetivos da leitura do manual e de jogar jogos. Em primeira análise, o objetivo principal desse processo parece ser simples e direto: vencer o jogo. Entretanto, o processo de transposição da teoria das regras para o contexto real do jogo é complexo, e normalmente demanda que seja feita uma partida preliminar, para testar as regras na prática e, então, compreendê-las na íntegra. Portanto, é prudente determinar objetivos menores e mais compatíveis com diferentes etapas da apreensão e compreensão das regras:
A primeira vez quando se joga um jogo, as expectativas devem ser baixas. Jogar uma primeira partida é como fazer uma primeira panqueca: ela pode acabar mal cozida, mal formada, e geralmente é insossa em comparação com as que seguem. Quando se joga um jogo pela primeira vez, você provavelmente terá que jogar sem conseguir formar estratégias complexas ou mesmo compreender completamente as implicações das escolhas que está fazendo. Você ainda pode perceber, no decorrer do jogo, que você entendeu mal as regras desde o começo e que a primeira partida inteira do jogo foi "inútil". Para jogadores, a primeira partida (como a primeira panqueca) é um investimento na segunda. Jogadores toleram a primeira partida desajeitada e levemente desagradável na esperança que as partidas posteriores justificarão o esforço. (HAM, 2016) ${ }^{3}$

Em função desse processo, fica evidente que um dos desafios do manual é contextualizar as regras em situações práticas de jogo, permitindo que os usuários compreendam a forma como podem - e, mais importante, devem - ser aplicadas. Tendo isso em mente, é importante relembrar da determinação do Código de Defesa do Consumidor sobre a necessidade do uso de imagens ilustrativas nos manuais.

Portanto, faz-se referência ao Edital de Convocação de 2018 da Coordenação-Geral dos Programas do Livro (CGPLI), que estabeleceu que os livros didáticos devem "Utilizar ilustrações que dialogam com o texto"; ao texto de Macklin (2015), caracterizando os recursos gráficos dos manuais como canais de contextualização da informação não triviais; e ao artigo de Tufte (2001), defendendo que imagens, tabelas e gráficos devem ser apresentadas próximas dos textos que fazem referência a elas, de modo que o fluxo de

\footnotetext{
${ }^{3}$ Tradução livre de: The first time you play a game, expectations should be low. The first game is like the first pancake-it can be half-cooked, malformed, and generally pales in comparison to what follows. When you play a game for the first time, you will likely have to play without being able to form a larger strategy or even fully understand the implications of the choices you are making. You may even realize late in the game that you have misunderstood the rules all along and that the entire play session was "pointless." For game players, the first game (like the first pancake) is an investment in the second one. Players put up with the clunky, slightly unpleasant first game in hopes that the later games will justify the effort.
} 


\section{$17^{\circ}$ ERGODESIGN \& USIHC 2019}

PUC-Rio, 11 a 13 de dezembro

Rio de Janeiro, RJ, Brasil $17^{\circ}$ Ergodesign - Congresso Internacional de Ergonomia e Usabilidade de Interfaces Humano Tecnológica: Produto, Informações Ambientes Construídos e Transporte

$17^{\circ}$ USIHC - Congresso Internacional de Ergonomia e Usabilidade de Interfaces Humano Computador

leitura não seja interrompido e as informações possam ser devidamente interpretadas. De acordo com o autor, sacrificar o fluxo de leitura em prol de especificações de produção fere a usabilidade textual, devendo-se adotadas diretrizes para os manuais "com ênfase para a lógica de utilização em vez da lógica de funcionamento" (MORAES, 2003).

Na prática, esses direcionamentos foram incorporados na dissertação de Duarte (2015) para a Universidade Federal do Paraná (UFPR), visto que foi compreendido pelo autor - e aprovado Colegiado de Representação Discente do PPGDesign da UFPR - que esta proposta de diagramação de fato torna as informações mais contextualizadas, facilitando a compreensão dos leitores, considerando

Já no contexto dos jogos de tabuleiro, alguns manuais já apresentam imagens contextualizadoras. Entretanto, elas estão majoritariamente presentes nas seções onde está sendo explicada a montagem do tabuleiro (se houver) e a preparação da partida de jogo geralmente, nas primeiras páginas. No decorrer do texto, quando algum exemplo prático precisa ser apresentado, isto costuma ocorrer com texto corrido, escrito por extenso.

Sobre a questão da ordem das informações, também é importante levar em consideração o contexto em que elas devem aparecer (MACKLIN, 2015). No texto, o autor definir clara e diretamente que um dos parâmetros de contextualização das informações dentro de uma categoria é se ela, de fato, faz parte dessa categoria: na seção sobre "preparação da partida", não é prudente se aprofundar em "ações dos jogadores", por mais que qualquer informação pertinente possa ser mencionada brevemente, caso necessário. Ademais, para estabelecer o parâmetro para a organização das categorias e seções do manual, faz-se um paralelo com o texto de Broadbent:

A compreensão é melhor se a sequência de palavras corresponde à sequência temporal dos eventos (CLARK, 1971). Portanto, espera-se que se as partes de uma máquina se encontram uma após a outra, pode ser melhor que as instruções mencionem a parte que se encontre antes, mesmo que isso signifique colocar a frase na forma passiva. (BROADBENT, 1977)

O autor conclui que, apesar das frases nas formas ativa, passiva e negativa, apresentarem lógicas semelhantes, a decisão de qual das versões será utilizada não deve se basear em decisões arbitrárias e teóricas, mas no contexto do usuário que deve interpretá-las. Portanto, na situação em que o jogador deve se tornar capaz de aprender as regras do jogo - que, na maioria dos casos, devem ser aplicadas em ordens específicas -, a forma mais simples de se adequar a ela é apresentando cada uma das categorias de informações na ordem em que elas de fato aparecem e acontecem no jogo.

No artigo "A Closer Look at the (Rule-) Books: Framings and Paratexts in Tabletop Role-playing Games"5 (JARA, 2011), o autor explica que um importante elemento na compreensão de qualquer texto é o pode ser chamado de Framing ${ }^{6}$ (WOLF, 2006: 5) ou de Paratexto (GENETTE, 1997): elementos complementares ao texto cuja raison d'être ${ }^{7}$ é auxiliar no processo de leitura, imersão e interpretação do texto. Eles são múltiplos e variados, incluindo a capa do texto, título, ilustrações, notas de rodapé, comentários e -

\footnotetext{
${ }^{4}$ Tradução Livre de "Understanding is better if the sequence of words in the sentence corresponds to the sequence of events in time (Clark, 1971). One can expect therefore that if the parts of some machine are encountered one after another, that it may be better for the instructions to mention first that part which is encountered first, even though this means putting the sentence in the passive."

${ }^{5}$ Um Olhar Mais Atento aos Livros (Guias): Molduras e Paratextos em Jogos Analógicos de Interpretação de Personagens. (Tradução Livre)

${ }^{6}$ Moldura (Tradução Literal), porém ela não traduz o significado exato, tendo-se mantido o termo.

7 "Razão de Ser" (Tradução Literal), questão filosófica ou ideológica que confere significado à algo.
} 


\section{$17^{\circ}$ ERGODESIGN \& USIHC 2019}

PUC-Rio, 11 a 13 de dezembro

Rio de Janeiro, RJ, Brasil $17^{\circ}$ Ergodesign - Congresso Internacional de Ergonomia e Usabilidade de Interfaces Humano Tecnológica: Produto, Informações Ambientes Construídos e Transporte

$17^{\circ}$ USIHC - Congresso Internacional de Ergonomia e Usabilidade de Interfaces Humano Computador

especialmente - prefácio. Esses elementos precisam estar alinhados com o objetivo da leitura visto que ele está intimamente ligado com a forma e a qualidade do processo de leitura (UNGER, 2003). Dessa forma, no momento do primeiro contato com o manual, o objetivo da leitura deve ser a introdução do usuário às mecânicas, temáticas e regras, visto que essas são as condições essenciais para que o jogo ocorra tranquilamente:

Por sua vez, estas regras são um fator muito importante para o conceito de jogo. Todo jogo tem suas regras. São estas que determinam aquilo que "vale" dentro do mundo temporário por ele circunscrito. As regras de todos os jogos são absolutas e não permitem discussão. Uma vez, de passagem, Paul Valéry exprimiu uma ideia das mais importantes: "No que diz respeito às regras de um jogo, nenhum ceticismo é possível, pois o princípio no qual elas assentam é uma verdade apresentada como inabalável". E não há dúvida de que a desobediência às regras implica a derrocada do mundo do jogo. O jogo acaba: o apito do árbitro quebra o feitiço e a vida "real" recomeça. (HUIZINGA, 2014: 14).

Huizinga explica, em suas palavras, um processo de Suspensão de Descrença proporcionado para o usuários pelo jogo, por meio do qual eles aceitam temporariamente a verossimilhança interna dele (CARVALHO, LÉSTE, MONT'ALVÃO, 2019). Portanto, no meio dos jogos de tabuleiro, o prefácio equivale ao elemento que permite a imersão dos usuários no "mundo" do jogo, que pode-se chamar de "contexto temático" ou "introdução" que, apesar de não fazer parte oficial das regras, explica o funcionamento da lógica interna do jogo e do universo, muitas vezes fictício e fantasioso, onde ele se passa.

De acordo com Jara (2011), esta é uma prática comum em manuais de Role Playing Games (RPGs), analógicos, e a análise dele indica que a presença desse elemento introdutório anterior ao texto que explica as regras do jogo, porém dentro do mesmo livro, faz com que ele seja percebido como complementar à diegese do jogo, ao passo que existe fora dela. Portanto, ela serve ao propósito de contextualizar as ações e decisões que serão tomadas no jogo, traduzindo-as para o usuário e, portanto, conferindo-lhes significado real.

Outro paratexto importante, já presente em diversos manuais, é um glossário informativo sobre termos específicos que estejam associados à temática do jogo, muitas vezes não sendo de uso comum ou possuindo significados variantes das definições de dicionários - e, por vezes, até tendo sido inventados especificamente para o jogo. Normalmente, eles estão presentes no começo ou no final dos manuais, porém, considerando que fazem parte do processo de familiarização dos jogadores com termos importantes para o contexto do jogo, recomenda-se que estejam presentes no começo.

\subsection{Diretrizes Preliminares}

A partir dos autores e documentos citados, definiram-se as seguintes diretrizes e guidelines, que devem estar organizadas na ordem em que estão apresentadas a seguir:

1) O texto do manual deve ser precedido de um paratexto introdutório que explique o universo do jogo, além de suas leis de funcionamento interno: o Contexto Temático, ou Introdução - que pode mencionar o objetivo do jogo, brevemente;

2) Caso necessário, deve haver um Glossário que defina sucintamente o significado de termos chave para o jogo que, se não explicados, possam gerar algum tipo de desentendimento ou falha de interpretação; 


\section{$17^{\circ}$ ERGODESIGN \& USIHC 2019}

PUC-Rio, 11 a 13 de dezembro Rio de Janeiro, RJ, Brasil $17^{\circ}$ Ergodesign - Congresso Internacional de Ergonomia e Usabilidade de Interfaces Humano Tecnológica: Produto, Informações Ambientes Construídos e Transporte

$17^{\circ}$ USIHC - Congresso Internacional de Ergonomia e Usabilidade de Interfaces Humano Computador

3) A fim de significar o aprendizado das regras para o contexto do usuário, é necessário informar o que ele deve se tornar capaz de fazer ao final da apreensão das regras: neste caso, informar o Objetivo do Jogo. Porém, é importante frisar que o objetivo nunca deve oferecer uma afirmação genérica, a exemplo de "vencer o jogo", visto que isto não informa o jogador sobre nenhuma habilidade que desenvolverá;

4) As regras devem ser introduzidas na mesma ordem cronológica em que serão relevantes no jogo. Naturalmente, cada jogo possui mecânicas, componentes e regras únicas, fazendo com que essa etapa seja extremamente variável para cada um deles. Entretanto, recomenda-se que a primeira das seções do manual a ser introduzida seja o Preparo do Jogo, visto que todo jogo precisa começar a partir de um estado inicial, naturalmente;

5) Sempre que pertinente, devem ser usadas Figuras llustrativas que facilitem a compreensão das informações sendo apresentadas. Essas figuras devem estar próximas do conteúdo ao qual se referem, respeitando o fluxo de leitura natural do usuário. Ademais, recomenda-se que no mínimo os seguintes conteúdos sejam ilustrados: Preparo do Jogo demonstrando o estado inicial da mesa de jogo; Exemplos Práticos, demonstrando o estado do jogo antes e depois da ação ou evento sendo exemplificado; e Exemplos de Componentes, da primeira vez que forem mencionados nas regras (da primeira vez que uma carta seja mencionada, um exemplo de carta deve estar presente ao lado).

Em função das diretrizes definidas acima, foram analisados os manuais e video tutoriais referentes ao jogos mencionados na Introdução (Item 1), descrita a seguir.

\section{ANÁLISE EXPLORATÓRIA DOS MANUAIS E VIDEO TUTORIAIS}

Considerando que a imagem ajuda a contextualizar as informações textuais-verbais, os vídeos possuem mais capacidade de ilustrar cenários práticos de jogabilidade e mecânica do jogo, além do funcionamento e interação com os componentes, visto que o texto verbal é traduzido para o canal auditivo, ao passo que o canal visual recebe estímulos constantes dos efeitos dessas informações no tabuleiro e demais partes materiais do jogo. Além disso, como os vídeos apresentam estímulos audiovisuais, aumenta a acessibilidade para usuários cegos e analfabetos - considerando que há uma série de barreiras à interação com o documento escrito, tornando preferível o uso dos canais auditivos.

Por outro lado, para assistir vídeos publicados no YouTube é necessário acesso à internet - o que nem sempre será possível nem fará parte da realidade dos usuários.

Ademais, em se tratando de vídeos só é possível apreender as informações linearmente seguindo o fluxo temporal do vídeo -, enquanto a manipulação da minutagem do vídeo é difícil e depende de destreza para ser manipulada, especialmente em telas de celular. $\mathrm{O}$ manual, por contraste, pode ser folheado sem maiores problemas, além de possuir, geralmente, títulos para cada seção, facilitando a navegação e busca por informações.

Em seguida, foram avaliados tanto os manuais quando os vídeos encontrados para os jogos selecionados, comparando-se as características básicas de documentos que visam apresentar informações para usuários: idioma, tipo de linguagem, tamanho, indexação ${ }^{8}$, presença e ordenação das informações.

${ }^{8}$ O YouTube possibilita que sejam colocadas Marcações de Tempo (Time Stamps) nas descrições das páginas dos vídeos, que serão consideradas as indexações dos vídeos avaliados. 


\subsection{Coup - editora Mandala Jogos}

Foram analisados todos os manuais presentes na versão brasileira do jogo, além dos vídeos considerados como mais relevantes pela ferramenta de busca do YouTube.

Tabela 1 - Comparação Entre Manuais e Vídeo Tutoriais do Jogo Coup

\begin{tabular}{|c|c|c|c|c|c|c|c|c|c|c|c|c|c|c|c|c|c|c|c|c|c|c|c|}
\hline & 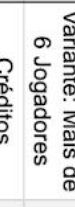 & 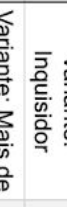 & & 童 & $\begin{array}{l}\text { 䍘 } \\
\text { 恶 } \\
\begin{array}{c}0 \\
0\end{array}\end{array}$ & 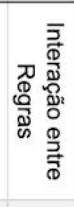 & 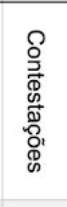 & 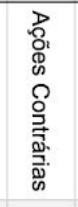 & 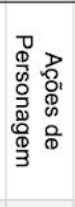 & 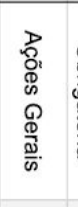 & 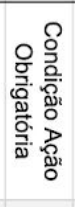 & 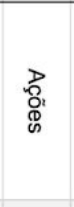 & 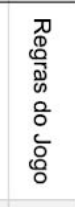 & @્@ & $\begin{array}{l}\frac{\circ}{\bar{\sigma}} \\
\frac{0}{\partial}\end{array}$ & 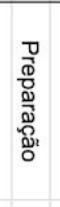 & 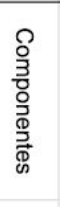 & 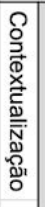 & & 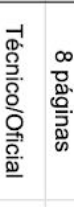 & 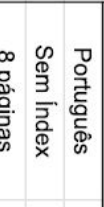 & & \\
\hline 1 & $\begin{array}{ll}1 \\
\end{array}$ & 1 & I & 1 & 1 & 1 & 1 & 1 & 1 & 1 & 1 & 1 & 1 & 1 & & 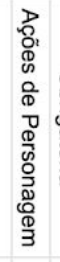 & 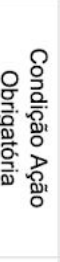 & 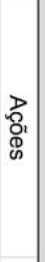 & & 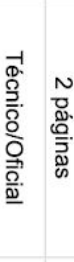 & 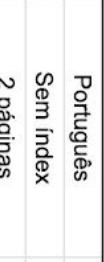 & & 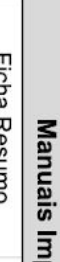 \\
\hline 1 & $\begin{array}{ll}1 \\
1\end{array}$ & 1 & I & 1 & 1 & 1 & 1 & 1 & 1 & 1 & 1 & 1 & 1 & 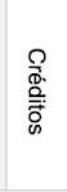 & 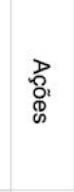 & 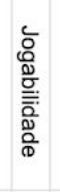 & 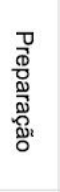 & 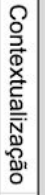 & & 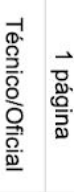 & 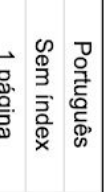 & & 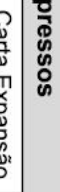 \\
\hline 1 & $\begin{array}{ll}1 \\
1\end{array}$ & I & I & 1 & 1 & 1 & 1 & 1 & 1 & 1 & 1 & 1 & 1 & 1 & $\begin{array}{l}0 \\
\vdots \\
\overrightarrow{0} \\
0 \\
0 \\
0 \\
00 \\
0 \\
0 \\
0 \\
0\end{array}$ & 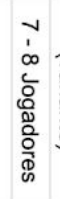 & 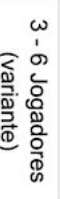 & 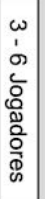 & & 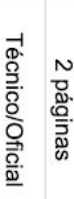 & 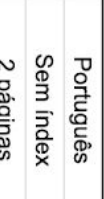 & & \\
\hline$\vec{\omega}$ & $\vec{\infty} \quad \vec{v}$ & $\vec{\sigma}$ & $\overrightarrow{5}$ & $\vec{c}$ & $\vec{A}$ & $\vec{\omega}$ & $\vec{N}$ & $\vec{\Xi}$ & $\overrightarrow{0}$ & 0 & $\infty$ & $v$ & o & or & $\triangle$ & $\omega$ & $N$ & $\overrightarrow{.}$ & & & & & \\
\hline 1 & $\begin{array}{ll}1 & 1\end{array}$ & I & 1 & 1 & 1 & 1 & 1 & 1 & 1 & 1 & 喬 & 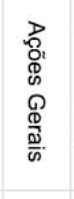 & 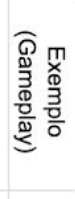 & $\begin{array}{l}\frac{0}{\overline{0}} \\
\frac{\overrightarrow{0}}{\tilde{\delta}}\end{array}$ & 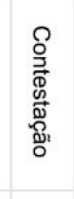 & 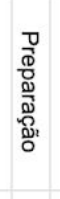 & @ & 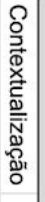 & 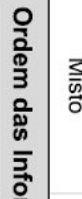 & 롬 & 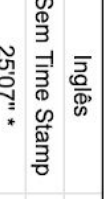 & 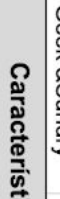 & \\
\hline 1 & 1 & I & I & 1 & 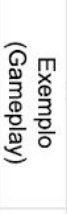 & 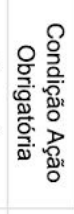 & 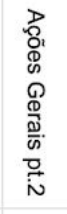 & 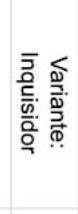 & 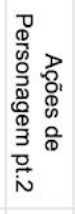 & 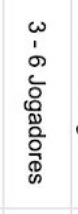 & 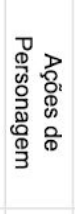 & \begin{tabular}{l}
$\frac{o}{0}$ \\
$\frac{0}{0}$ \\
\multirow{\delta}{*}{}
\end{tabular} & 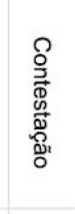 & 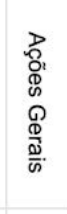 & 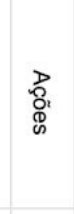 & 茅 & 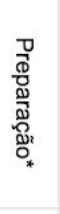 & 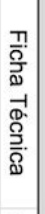 & 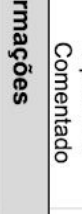 & 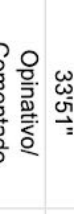 & 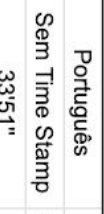 & क & \\
\hline 1 & 1 & I & I & 1 & 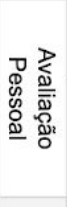 & 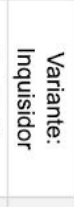 & 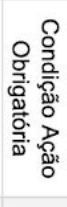 & 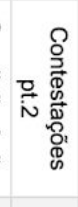 & 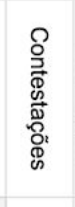 & 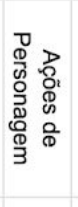 & 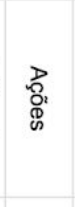 & 西 & 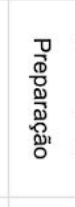 & 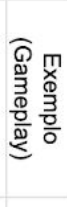 & 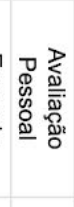 & 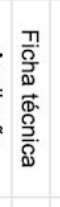 & $\begin{array}{l}\frac{0}{0} \\
\frac{0}{0} \\
\frac{0}{\Delta}\end{array}$ & 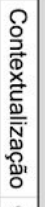 & & 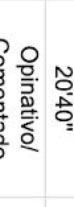 & 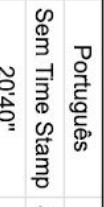 & & 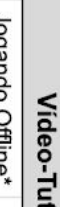 \\
\hline 1 & $\begin{array}{ll}1 \\
\end{array}$ & I & I & 1 & 1 & 1 & 1 & 1 & 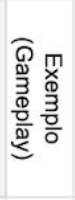 & 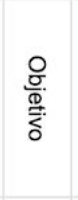 & 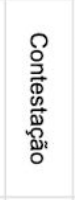 & 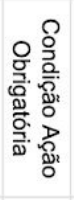 & 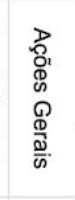 & 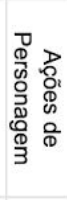 & $\stackrel{\infty}{\Phi}$ & 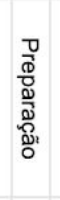 & 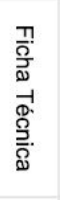 & 齐 & & 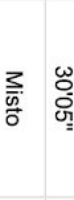 & 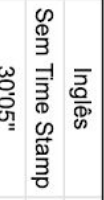 & & \\
\hline 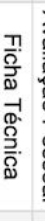 & 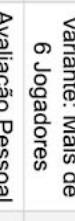 & 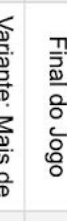 & 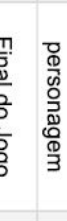 & 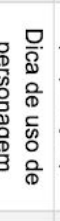 & 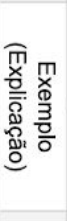 & 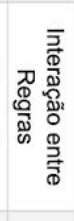 & 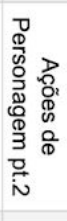 & 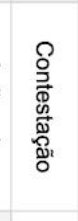 & 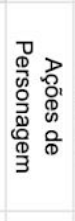 & 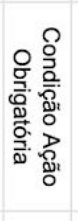 & 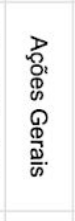 & 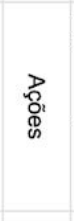 & 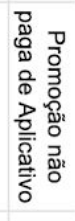 & 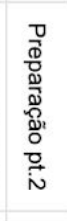 & $\frac{\stackrel{\circ}{\frac{0}{0}}}{\frac{0}{\grave{c}}}$ & 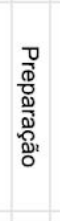 & 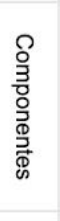 & 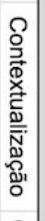 & & 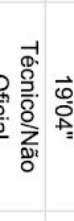 & 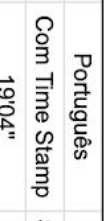 & & \\
\hline 1 & 11 & I & & 1 & 1 & 1 & 1 & 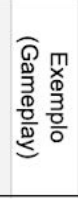 & 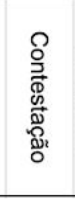 & 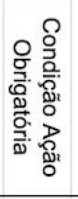 & 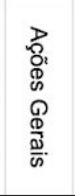 & 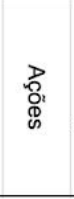 & 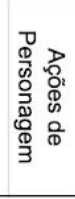 & 岕 & 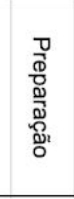 & 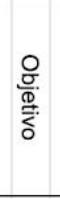 & 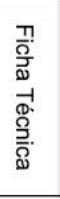 & & & 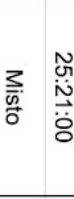 & 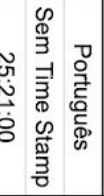 & & \\
\hline
\end{tabular}




\section{$17^{\circ}$ ERGODESIGN \& USIHC 2019}

PUC-Rio, 11 a 13 de dezembro

Rio de Janeiro, RJ, Brasil $17^{\circ}$ Ergodesign - Congresso Internacional de Ergonomia e Usabilidade de Interfaces Humano Tecnológica: Produto, Informações Ambientes Construídos e Transporte

$17^{\circ}$ USIHC - Congresso Internacional de Ergonomia e Usabilidade de Interfaces Humano Computador

Pelo caráter não oficial e opinativo de alguns dos vídeos, eles apresentam pouco rigor técnico, por vezes cometendo pequenos equívocos sobre algumas regras - ou até mesmo esquecendo de algumas delas. Em alguns deles, parte do tempo é dedicado à piadas, comentários não relativos diretamente às regras ou promoção de outros produtos e, na maioria, o tempo de exemplo de gameplay era muito mais extenso do que o tempo de explicação das regras. Dentre todos eles, o vídeo do canal Romir Playhouse foi o mais técnico, completo e o único que, além de possuir timestamp - mesmo que muito simples e pouco desenvolvida - não apresentou nenhum erro ou equívoco nas regras (sendo o único que não ficou marcado com asterisco na tabela). Todas essas diferenças podem ser explicadas pela variedade de propostas dos canais, visto que os vídeos são produções independentes da empresa produtora do jogo, não passando pelo mesmo crivo ao qual o manual foi submetido.

Já o manual, além de não possuir índex, apresenta ilustrações insuficientes.

Ademais, a decisão por separar determinadas partes das regras em manuais auxiliares fez com que muitas informações ficassem descentralizadas - não estando no manual oficial, que deveria ser unificador. Entretanto, a presença da ficha resumo é uma boa prática, que permite o acesso às informações essenciais do jogo com mais rapidez e facilidade.

Figura 1 - Excerto do manual de Coup, disponível no repositório Ludopédia, evidenciando as únicas ilustrações presentes nos manuais, referentes às cartas de personagens que existem no jogo base.
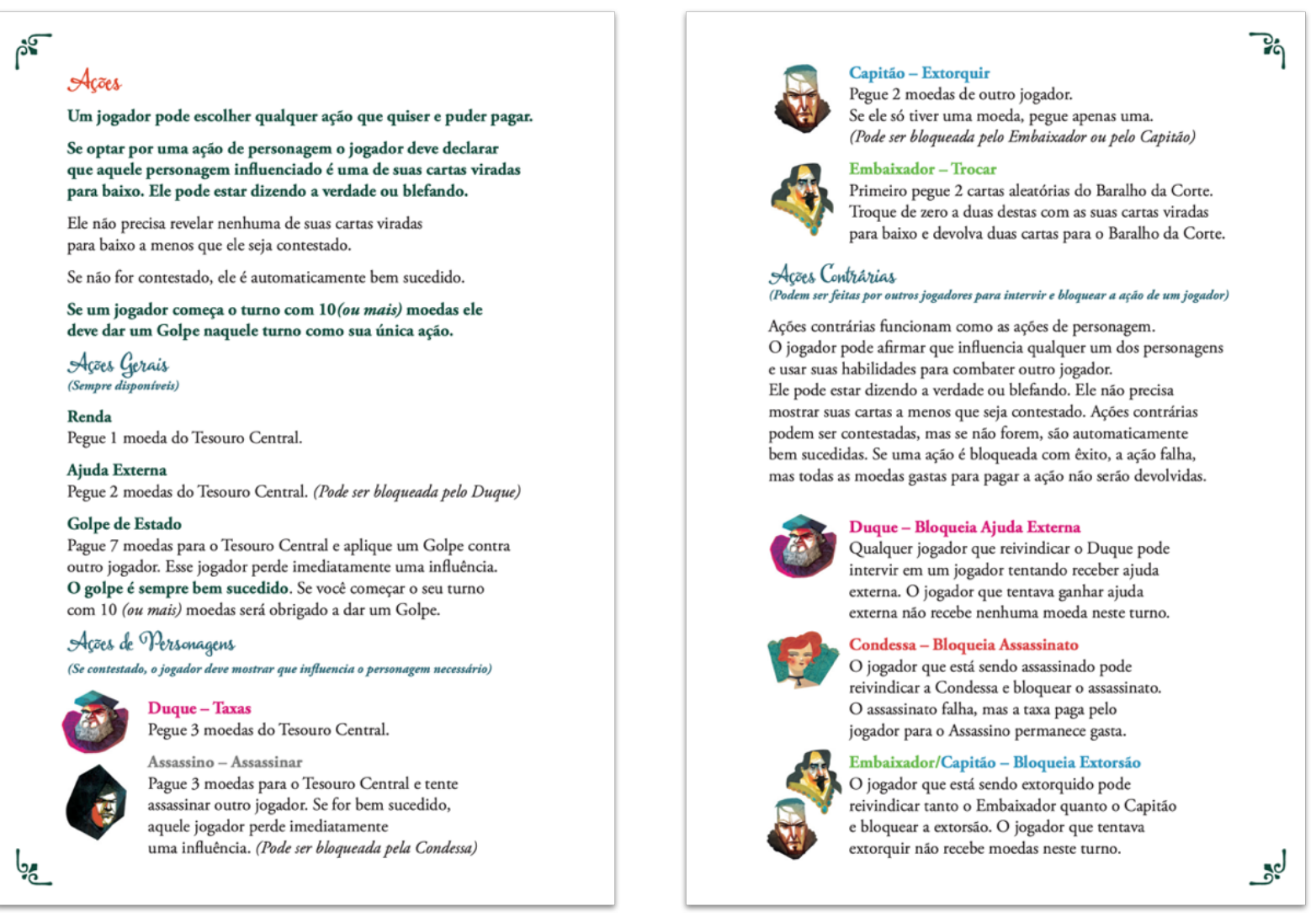

\subsection{Nemesis - editoras Rebel e Awakened Realms}

Considerando que só há um vídeo oficial para este jogo, não foi necessário fazer pré-seleção. O manual completo, entretanto, não está disponível online, tendo sido usada a versão do protótipo, parte do repositório de manuais de jogos do site Ludopédia. 


\section{$17^{\circ}$ ERGODESIGN \& USIHC 2019}

PUC-Rio, 11 a 13 de dezembro Rio de Janeiro, RJ, Brasil $17^{\circ}$ Ergodesign - Congresso Internacional de Ergonomia e Usabilidade de Interfaces Humano Tecnológica: Produto, Informações Ambientes Construídos e Transporte

$17^{\circ}$ USIHC - Congresso Internacional de Ergonomia e Usabilidade de Interfaces Humano Computador

Tabela 2 - Comparação entre Manual e Vídeo Tutorial de Nemesis

\begin{tabular}{|c|c|c|c|c|}
\hline \multicolumn{3}{|c|}{ Manuais Impressos } & \multicolumn{2}{|c|}{ Vídeo-Tutorial } \\
\hline \multicolumn{2}{|c|}{ Manual Principal - Protótipo } & \multicolumn{3}{|c|}{ Nemesis - How To Play } \\
\hline \multicolumn{5}{|c|}{ Características } \\
\hline \multicolumn{3}{|c|}{ Inglês } & \multicolumn{2}{|c|}{ Inglês } \\
\hline \multicolumn{3}{|c|}{ Sem Índex } & \multicolumn{2}{|c|}{ Com Time Stamp } \\
\hline \multicolumn{3}{|c|}{24 páginas } & \multicolumn{2}{|c|}{$50^{\prime} 03^{\prime \prime}$} \\
\hline \multicolumn{2}{|c|}{ Técnico/Oficial } & & \multicolumn{2}{|c|}{ Técnico/Oficial } \\
\hline \multicolumn{5}{|c|}{ Ordem das Informações } \\
\hline Componentes & Preparação & $1-2$ & Contextualização & Preparação \\
\hline Objetivo do Jogo & Turno & $3-4$ & Glossário & Fase do Jogador \\
\hline $\begin{array}{l}\text { Passo do Turno do } \\
\text { Jogador }\end{array}$ & Ações Básicas & $5-6$ & $\begin{array}{c}\text { Passo do Turno do } \\
\text { Jogador }\end{array}$ & $\begin{array}{c}\text { Passo das Ações do } \\
\text { Jogador }\end{array}$ \\
\hline Ações Especiais & Ações de Sala & $7-8$ & $\begin{array}{c}\text { Passo da Passagem } \\
\text { de Turno }\end{array}$ & Eventos \\
\hline Fase da Exploração & Rolagem de Sons & $9-10$ & $\begin{array}{c}\text { Passo do Faixa de } \\
\text { Tempo }\end{array}$ & $\begin{array}{c}\text { Passo do Ataque do } \\
\text { Intruso }\end{array}$ \\
\hline Intrusos & Eventos & $11-12$ & Dano por Fogo & $\begin{array}{l}\text { Resolvendo Cartas } \\
\text { de Eventos }\end{array}$ \\
\hline Regras Gerais & Portas & $13-14$ & $\begin{array}{l}\text { Desenvolvimento da } \\
\text { Bolsa de Intruso }\end{array}$ & $\begin{array}{l}\text { Condições de Fim de } \\
\text { Jogo }\end{array}$ \\
\hline Reparos & $\begin{array}{l}\text { Ataque aos } \\
\text { Jogadores }\end{array}$ & $15-16$ & Marcador de Tempo & Destruição da Nave \\
\hline Fim do Jogo & - & $17-18$ & Último Sobrevivente & Condições de Vitoria \\
\hline- & - & $19-20$ & Checagem do Motor & $\begin{array}{l}\text { Checagem das } \\
\text { Coordenadas }\end{array}$ \\
\hline- & - & $21-22$ & $\begin{array}{l}\text { Checagem da } \\
\text { Contaminação }\end{array}$ & $\begin{array}{c}\text { Checagem dos } \\
\text { Objetivos }\end{array}$ \\
\hline
\end{tabular}

No vídeo deste jogo, produzido pelo canal Board Game Replay ${ }^{9}$ as imagens representam quase exclusivamente o conteúdo e tabuleiro do jogo. Nos momentos em que figuras humanas são mostradas, somente as mãos ficam visíveis - sempre interagindo diretamente com os componentes, cumprindo o papel que um computador faria em jogos digitais (CARVALHO, LÉSTE, MONT'ALVÃO, 2019). Em comparação com os demais vídeos do mesmo canal, percebe-se uma clara discrepância tanto na escolha do enquadramento, que favorece as figuras humanas interagindo com o tabuleiro, quanto no discurso de caráter menos formal e mais opinativo, que tendem a focar no gameplay ${ }^{10}$ ao invés de na explicação técnica dos jogos sendo avaliados.

Portanto, levando em consideração que este é o único vídeo oficial do canal - e que ele segue a mesma linha narrativa que os vídeos oficiais de santorini - pode-se concluir que estas escolhas de direção e produção do vídeo parecem configurar a tendência das características de filmagem e de roteiro desse gênero específico de produto audiovisual.

\subsection{Santorini - editoras Spin Master, Roxley e Galápagos Jogos}

Foram analisadas as versões mais atuais dos manuais disponíveis online, tanto em português quanto em inglês, além de um total de 7 vídeos: um sobre a campanha de kickstarter do jogo, onde as regras são explicadas; um sobre a expansão do velocino dourado (indisponível no Brasil); e 5 para cartas de divindades, de forma que houvesse pelo menos uma carta representativa por cada grupo ${ }^{11}$ de divindades: (1) Cartas que podem ser usadas indiscriminadamente; (2) Cartas que só podem ser usadas em partidas de 2 ou 3 jogadores; (3) Cartas que só podem ser usadas em partidas de 2 jogadores; (4) Cartas que

\footnotetext{
${ }^{9}$ Disponível em: <https://www.youtube.com/user/boardgamereplay/featured> Acesso 11 set, 2019.

${ }^{10} \mathrm{~A}$ jogabilidade do jogo, que mescla as mecânicas com a experiência particular dos participantes.

11 Uma carta de divindade pode fazer parte de mais de um grupo de cartas. Também não foi considerado o grupo das Cartas de Heróis, visto que não há videos sobre elas. Acesso, 11 set. 2019.
} 
Tabela 3 - Comparação entre Manuais e Vídeo Tutoriais de Santorini

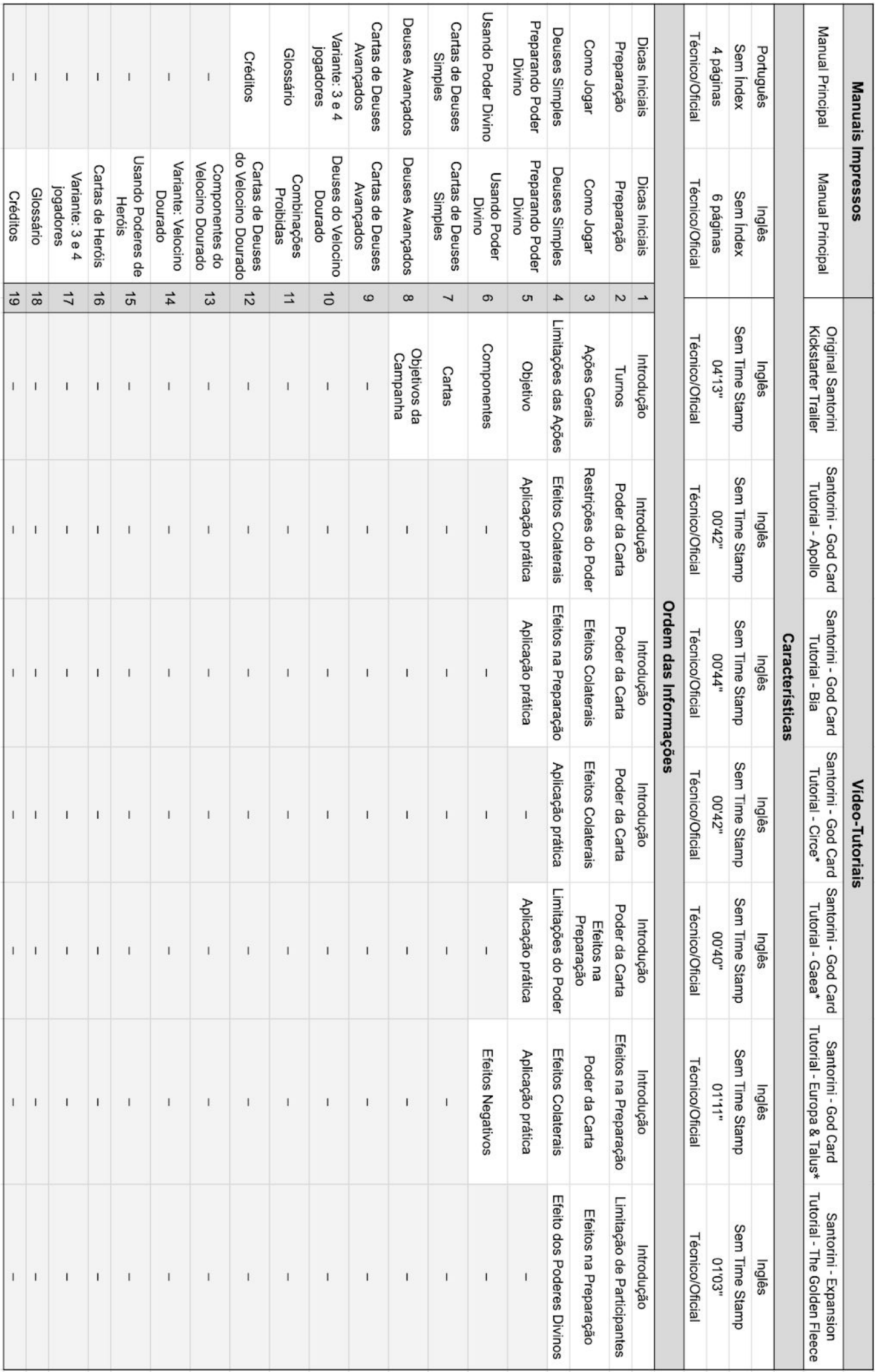




\section{$17^{\circ}$ ERGODESIGN \& USIHC 2019}

PUC-Rio, 11 a 13 de dezembro

Rio de Janeiro, RJ, Brasil $17^{\circ}$ Ergodesign - Congresso Internacional de Ergonomia e Usabilidade de Interfaces Humano Tecnológica: Produto, Informações Ambientes Construídos e Transporte

$17^{\circ}$ USIHC - Congresso Internacional de Ergonomia e Usabilidade de Interfaces Humano Computador

não podem ser usadas com a expansão do velocino dourado; (5) Cartas que não podem ser usadas em conjunto com outras cartas específicas; (6) Cartas de divindades avançados; (7) Cartas de divindades do Velocino Dourado.

Alguns dos vídeos de tutorial das god cards não apresentam todas as informações presentes nos manuais, nunca mencionando quando determinados deuses ou deusas não podem ser usados nas variantes de 3 ou 4 jogadores. Nos manuais impressos (e em suas versões digitais), essa informação está presente por meio de ícones acima do nome das cartas do deuses.

Dois exemplos de situações distintas podem ser observados a seguir (Figura 1), que demonstra a diferença da Deusa Circe, que só pode ser usada em partidas com 2 jogadores, e do Deus Hipnos, que pode ser usada em partidas de 2 a 4 jogadores, além de na expansão do Velocino Dourado.

Figura 2 - Excerto do manual de regras do jogo Santorini (versão em português, distribuído pela editora Galápagos no Brasil, disponível no repositório digital do site Ludopédia).
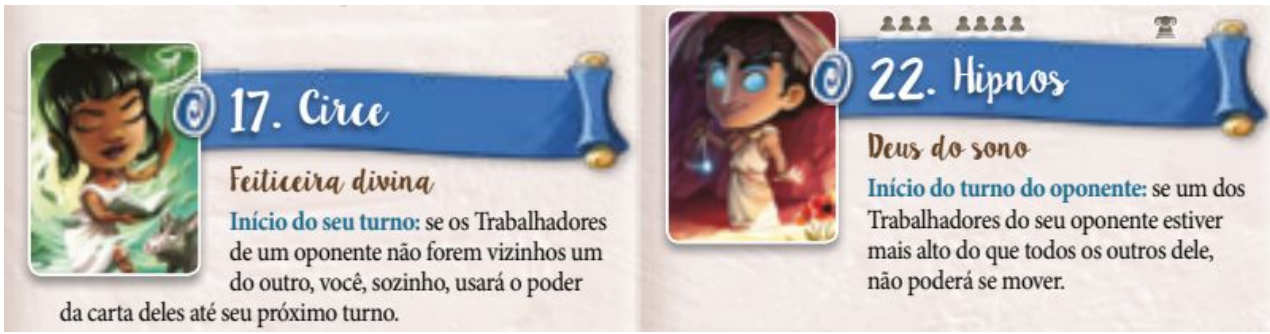

Ademais, o manual impresso de Santorini, em ambos os idiomas, apresenta ilustrações adequadas no geral, tanto que ilustram tanto as cartas de divindades sendo mencionadas quanto as situações de jogo descritas, evidente a seguir:

Figura 3 - Página 1 do manual de regras do jogo Santorini (versão em português, distribuído pela editora Galápagos no Brasil, disponível no repositório digital do site Ludopédia).

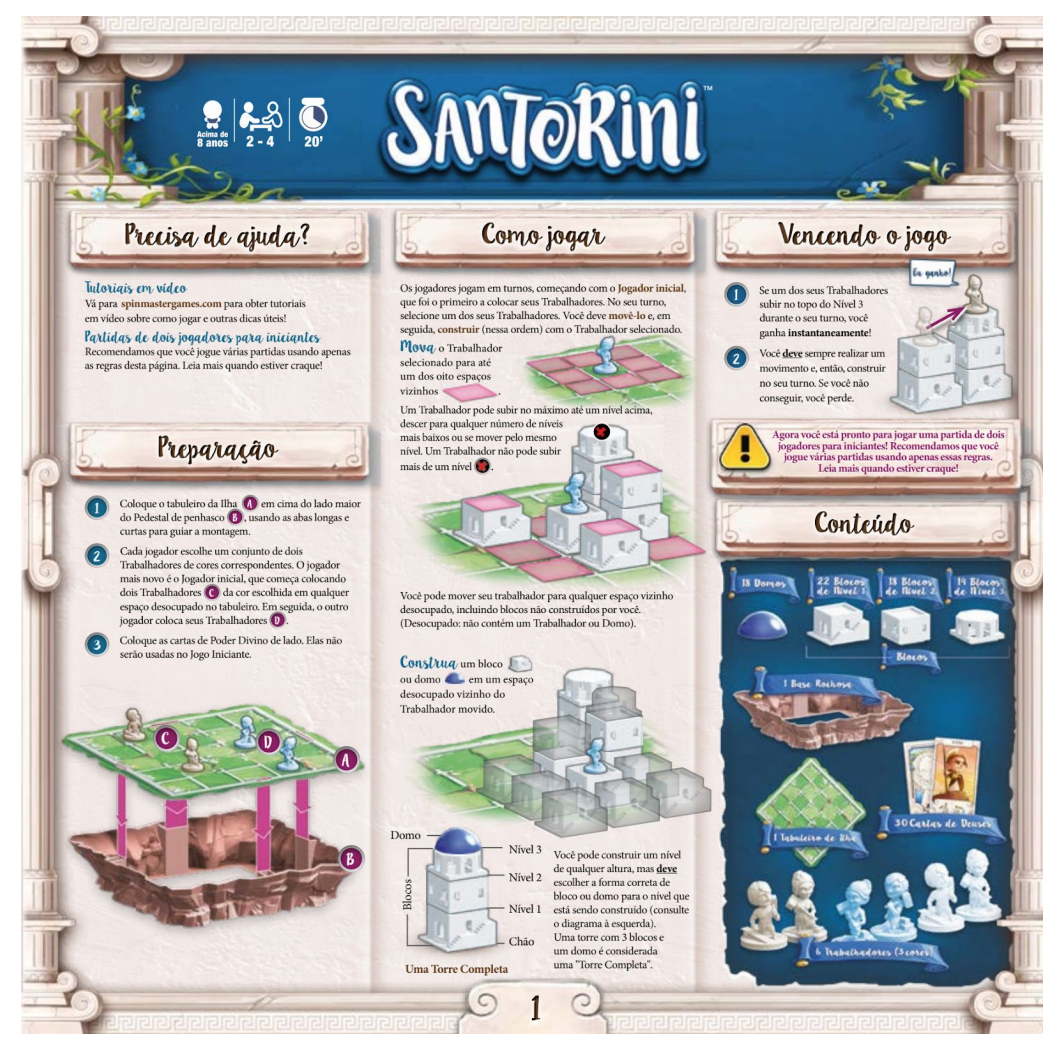




\section{$17^{\circ}$ ERGODESIGN \& USIHC 2019 \\ PUC-Rio, 11 a 13 de dezembro \\ Rio de Janeiro, RJ, Brasil}

$17^{\circ}$ Ergodesign - Congresso Internacional de Ergonomia e Usabilidade de Interfaces Humano Tecnológica: Produto, Informações Ambientes Construídos e Transporte

$17^{\circ}$ USIHC - Congresso Internacional de Ergonomia e Usabilidade de Interfaces Humano Computador

Mesmo com a grande quantidade de vídeos no canal, não há sobre todas as cartas - o que é um problema, caso essa fosse a fonte primária de acesso às regras. Ademais, 0 único vídeo que faz menção às regras base do jogo é o vídeo da campanha de financiamento coletivo do site Kickstarter. Porém, não há menção disso no título dificultando o acesso a essa informação.

Entretanto, a formatação dos vídeos em pequenos trechos das regras, específicos para cada carta, permite que eles sejam produzidos gradativamente para novas expansões. Para manuais impressos, seria necessário revisar o manual (tornando o anterior obsoleto) ou gerar um anexo (descentralizando as informações e interferindo na ordenação das informações na ordem em que se aplicam ao jogo) - e nenhuma das alternativas é ideal.

\section{CONCLUSÃO E PRÓXIMOS PASSOS}

Mesmo que a legislação brasileira indique a necessidade dos manuais de instruções de qualquer produto comercializado sejam didáticos, não há nenhuma regulamentação que indique o que, na prática, isso significa. Isto reflete a ausência de organização sistematizada das categorias de informações e de critérios comuns para os projetos gráficos dos manuais.

Em função disso, surge o nicho de produção de vídeo tutoriais que buscam sanar questões de usabilidade dos manuais - que não está plenamente consolidado no Brasil, apresentando algumas inadequações.

Portanto, o presente artigo realizou uma pesquisa bibliográfica interdisciplinar em material das áreas de educação, ergonomia, psicologia e estudos lúdicos, para de definir diretrizes que possam sanar essas questões. Em sequência, foi realizada uma pesquisa documental para selecionar jogos sobre os quais existem vídeo tutoriais, para que essas diretrizes fossem aplicadas tanto aos manuais quanto aos vídeos em questão - além da ordenação das informações presentes neles.

Tendo isso em mente, é possível constatar que nenhum dos documentos apresentados anteriormente se adequa completamente à proposta de controle de qualidade da seção 3.1, seja por ordenação inadequada, falta de indexação, utilização insuficiente ou descontextualizada de imagens, ausência de informações completas, presença de informações erradas - ou, em casos mais graves, combinações desses fatores.

Desta forma, entende-se que o presente artigo atingiu todos os seus objetivos, ao apresentar uma proposta de diretrizes baseada em conceitos de campos do conhecimento complementares e pertinentes à questão - aplicando-a ao contexto real do mercado de jogos analógicos, ao mensurar as características dos documentos selecionados.

Os resultados aqui apresentados, além de úteis para qualquer pesquisa que vise estudar a qualidade de manuais de jogos, são de fácil replicabilidade, dependendo somente da disponibilidade dos pesquisadores se propondo a realizar o estudo e do acesso aos manuais, disponíveis nos repositórios evidenciados no presente artigo.

Para dar sequência à pesquisa, considera-se pertinente reformular manuais presentes no mercado em função das diretrizes aqui apresentadas. Após a reformulação, devem ser realizados testes com usuários, a fim de medir se há impacto positivo no processo de apreensão, compreensão e aplicação das regras.

Caso haja, os jogadores terão se tornado mais competentes nas tarefas que pretendem desempenhar, em função do acesso facilitado às informações pertinentes ao contexto. Dessa forma, a verossimilhança interna do jogo estará mais protegida - o que, consequentemente, proporciona experiências mais proveitosas e positivas aos usuários, que deve ser o objetivo principal de qualquer estudo ergonômico. 


\section{REFERÊNCIAS BIBLIOGRÁFICAS}

BARON, R. A.; KALSHER, M. J. Psychology: From Science to Practice, Capítulo 6. Allyn \& Bacon, Boston, 2005

BRASIL, [ANVISA], Resolução - RDC No 360. 2003. Disponível em:

.http://portal.anvisa.gov.br/documents/33880/2568070/res0360_23_12_2003.pdf/5d4fc713-9 c66-4512-b3c1-afee57e7d9bc. Acesso em: 11 set. 2019.

BRASIL, [Ministério da Educação] Guia do Programa Nacional do Livro Didático. 2019. Disponível em:

https://pnld.nees.com.br/assets-pnld/guias/Guia_pnld_2020_pnld2020-projetos-integradores -1.pdf. Acesso em: 13 set. 2019

BRASIL. Código de Defesa do Consumidor e Normas Correlatas. - 2. ed. - Brasília: Senado Federal, Coordenação de Edições Técnicas, 2017. Disponível em:

https://www2.senado.leg.br/bdsf/bitstream/handle/id/533814/cdc_e_normas_correlatas_2ed. pdf. Acesso em: 08 set. 2019.

BRASIL. Edital de Convocação 01/2018 - CGPLI Edital de Convocação para o Processo de Inscrição e Avaliação de Obras Didáticas e Literárias para o Programa Nacional do Livro e do Material Didático PNLD 2020. 2018. Disponível em:

https://www.fnde.gov.br/programas/programas-do-livro/consultas/editais-programas-livro/ite m/11555-edital-pnld-2020. Acesso: 15 set. 2019.

BROADBENT, Donald Eric. Language and Ergonomics. Applied Ergonomics, Inglaterra, v. 8.1, p. 15-18, março 1977.

CARVALHO, M. C.; LÉSTE, J. V.; MONT'ALVÃO, C. Manuais de Jogos Enquanto Objetos Educativos: o desenvolvimento de estratégia em jogos analógicos como situações de aprendizado. SBGames, V. 18, in press.

CHAPANIS, Alphonse. Words Words Words. $8^{\circ}$ Encontro Anual da Human Factors Society. V. 7, n. 1, p. 1-17, Maryland, Estados Unidos da América, 1965.

DUARTE, Luiz Cláudio Silveira. Traços Distintivos de Estratégias em Jogos. 2015. Dissertação (Mestrado em Design) - Programa de Pós-Graduação em Design, Universidade Federal do Paraná, Paraná, 2015.

FRACALANZA, H.; NETO, J. M. O Livro Didático de Ciências: Problemas e Soluções. Ciência \& Educação (Bauru). Programa de Pós-Graduação em Educação para a Ciência, Universidade Estadual Paulista (UNESP), Faculdade de Ciências, campus de Bauru., v. 9, n. 2, p. 147-157, 2003. 


\section{$17^{\circ}$ ERGODESIGN \& USIHC 2019}

PUC-Rio, 11 a 13 de dezembro Rio de Janeiro, RJ, Brasil $17^{\circ}$ Ergodesign - Congresso Internacional de Ergonomia e Usabilidade de Interfaces Humano Tecnológica: Produto, Informações Ambientes Construídos e Transporte

$17^{\circ}$ USIHC - Congresso Internacional de Ergonomia e Usabilidade de Interfaces Humano Computador

FREITAS, N. K., RODRIGUES, M. H. O Livro Didático ao Longo do Tempo: a forma do conteúdo. $\mathbf{1 8}^{\circ}$ Seminário de Iniciação Científica. Universidade do Estado de Santa Catarina, 2008.

GAGNÉ, R. M. Como se Realiza a Aprendizagem. 1ª Edição, Reimpressão. Rio de Janeiro: Ao Livro Técnico S. A., 1973.

HAM, Ethan. Tabletop Game Design for Video Game Designers. Focal Press. Burlington, Boston, Estados Unidos da América, 2016.

HUIZINGA, Johan. Homo Ludens: o jogo como elemento da cultura. $8^{a}$ Edição. São Paulo: Perspectiva, 2018.

JARA, David. A Closer Look at the (Rule-) Books: Framings and Paratexts in Tabletop Role-playing Games. International Journal of Role-Playing, n. 4, University of Tampere, Finland, Abril, 2012.

KURTZ, L. B. CARRION, R. C. A. Inception! A Relação do Jogador com a Materialidade da Plataforma Tabletop Simulator. SBGames, Volume 17, p 948-951,Paraná, outubro 2018.

MACKLIN, Ryan. 11 Rules for Board Game Rules Writing. 6 fev, 2015. Disponível em: http://ryanmacklin.com/2015/02/11-rules-board-game-writing/. Acesso em: 10 set. 2019.

MORAES, A. Ergonomia e projeto de produtos, informação, interfaces da interação homem-computador e espaços arquiteturais: ensino e pesquisa, XXIII Encontro Nac. de Eng. de Produção - Ouro Preto, MG, Brasil, 2003.

TUFTE, Edward Rolf. The Visual Display of Quantitative Information. Graphics Press, Cheshire Connecticut, 1983.

Unger, G. Legible? Emigre, n. 65, p. 100-111, 2003. Disponível em: https://www.emigre.com/Essays/Magazine/Legible. Acesso em: 10 set. 2019.

\subsection{Vídeo tutoriais assistidos}

COUP - Como Jogar. [S. I.: s. n.], 2017. 1 video (19 min). Publicado pelo canal Romir Play House. Disponível em: https://www.youtube.com/watch?v=6UpW8dV2Oks. Acesso em: 11 set. 2019.

COUP - Review por Jogando Offline (s02e01). [S. I.: s. n.], 2014. 1 video (24 min). Publicado pelo canal Jogando Offline. Disponível em: https://www.youtube.com/watch?v=NB7rwNVHBgo Acesso em: 11 set. 2019. 


\section{$17^{\circ}$ ERGODESIGN \& USIHC 2019}

PUC-Rio, 11 a 13 de dezembro Rio de Janeiro, RJ, Brasil $17^{\circ}$ Ergodesign - Congresso Internacional de Ergonomia e Usabilidade de Interfaces Humano Tecnológica: Produto, Informações Ambientes Construídos e Transporte

$17^{\circ}$ USIHC - Congresso Internacional de Ergonomia e Usabilidade de Interfaces Humano Computador

FOI GOLPE | Gigante Leo, Defante, Jhonny, Rosana e Ulisses Mattos jogam COUP | De Quem é a Vez? [S. I.: s. n.], 2019. 1 video (25 min) Publicado pelo canal Rafael Studart. Disponível em: https://www.youtube.com/watch?v=bwbaMEPm1dY. Acesso em: 11 set. 2019.

JACK Explicador - Coup. [S. I.: s. n.], 2014. 1 video (33 min). Publicado pelo canal Meeple TV. Disponível em: https://www.youtube.com/watch?v=nwWCJdN32wA. Acesso em: 11 set. 2019.

LET'S Play COUP feat. Brennan Lee Mulligan from CollegeHumor | Overboard, Episode 12. [S. I.: s. n.], 2019. 1 video (30 min). Publicado pelo canal Polygon. Disponível em: https://www.youtube.com/watch?v=BrjCPnbEMfE. Acesso em: 11 set. 2019.

LOVE Letter \& Coup: Fine Brothers and Felicia Day Join Wil Wheaton. [S. I.: s. n.], 2015. 1 video (44 min). Publicado pelo canal Geek \& Sundry. Disponível em:

https://www.youtube.com/watch?v=k2YUYPDq7gQ. Acesso em: 11 set. 2019.

NEMESIS - How To Play. [S. I.: s. n.], 2019. 1 video (50 min). Publicado pelo canal Board Game Replay. Disponível em: https://www.youtube.com/watch?v=g1NnAHptaeE. Acesso em: 11 set. 2019.

ORIGINAL Santorini Kickstarter Campaing. [S. I.: s. n.], 2018. 1 video (4 min) Publicado pelo canal Roxley. Disponível em: https://www.youtube.com/watch?v=IBfGD8aq7Is\&. Acesso em: 13 set. 2019.

SANTORINI - Expansion Tutorial - The Golden Fleece. [S. I.: s. n.], 2016. 1 video (1 min) Publicado pelo canal Roxley. Disponível em: https://www.youtube.com/watch? v=fKQSQCisWTI. Acesso em: 13 set. 2019.

SANTORINI - God Card Tutorial - Apollo. [S. I.: s. n.], 2016. 1 video (1 min) Publicado pelo canal Roxley. Disponível em: https://www.youtube.com/watch?v=95EHcOSfwsY. Acesso em 13 set, 2019.

SANTORINI - God Card Tutorial - Bia. [S. I.: s. n.], 2016. 1 video (1 min) Publicado pelo canal Roxley. Disponível em: https://www.youtube.com/watch?v=rENxFkF04aw. Acesso em: 13 set. 2019.

SANTORINI- God Card Tutorial - Circe. [S. I.: s. n.], 2016. 1 video (1 min) Publicado pelo canal Roxley. Disponível em: https://www.youtube.com/watch?v=Z7RY6w2wGt0. Acesso em: 13 set. 2019.

SANTORINI - God Card Tutorial - Europa \& Talus. [S. I.: s. n.], 2018. 1 video (1 min) Publicado pelo canal Roxley. Disponível em: https://www.youtube.com/watch? $\mathrm{v}=2 \mathrm{gOzU}$ efcL68. Acesso em: 13 set. 2019. 
$17^{\circ}$ USIHC - Congresso Internacional de Ergonomia e Usabilidade de Rio de Janeiro, RJ, Brasil

SANTORINI - God Card Tutorial - Gaia. [S. I.: s. n.], 2019. 1 video (1 min) Publicado pelo canal Roxley. Disponivel em: https://www.youtube.com/watch?v=9ufsYvR19Aw. Acesso em: 13 set. 2019.

\section{Agradecimentos}

O presente trabalho foi realizado com apoio da Coordenação de Aperfeiçoamento de Pessoal de Nível Superior - Brasil (CAPES) - Código de Financiamento 001

Agradecimento especial à Júlia Martins N., que auxiliou na interpretação das legislações pertinentes ao desenvolvimento do presente artigo. 